\title{
NOTA SOBRE O CONCEITO DE "REFORMAS REVOLUCIONÁRIAS” DE ANDRÉ GORZ
}

\author{
Josué Pereira da Silva *
}

\begin{abstract}
Este artigo discute a relevância contemporânea do conceito de "reformas revolucionárias", elaborado por André Gorz na década de 1960 e por ele retomado em seus escritos mais recentes. Minha tese aqui é que tal conceito continua atual e tem sido apropriado, direta ou indiretamente, por outros teóricos sociais contemporâneos, ainda que, muitas vezes, esses últimos utilizem uma linguagem diferente. Para tanto, começo por apresentar, em linhas gerais, os contornos do conceito. Em seguida, mostro como ele foi utilizado por Gorz ao longo de seus escritos; e, por fim, eu o discuto a partir dos trabalhos de outros autores, focando em alguns temas dos debates contemporâneos.
\end{abstract}

Palavras-chave: André Gorz. Reformas revolucionárias. Tempo de trabalho. Renda básica.

\section{INTRODUÇÃO}

A revolução microeletrônica permite produzir quantidades crescentes de mercadorias com um volume decrescente de trabalho, de sorte que cedo ou tarde o sistema deve chegar a seus limites internos. O capitalismo que se automatiza até à morte deverá buscar sobreviver por uma distribuição de poder de compra que não corresponde ao valor de um trabalho. (Gorz, 2007b) ${ }^{1}$

Somente uma economia liberada da lei do valor pode colocar a produção a serviço do desenvolvimento humano, em vez de pôr os homens a serviço da produção de mercadorias. (Gorz, 2007a)

Entre as diversas contribuições de André Gorz para a teoria social crítica, o conceito de "reformas revolucionárias" destaca-se, em particular, por ser um articulador de praticamente toda sua produção teórica. Ele foi elaborado durante a década de 1960 para responder aos impasses da estratégia até então dominante no movimento operário europeu daque-

* Universidade Estadual de Campinas (UNICAMP). Departamento de Sociologia.

Rua Cora Coralina, 100 - Cidade Universitária Zeferino Vaz. Barão Geraldo. Cep: 13083-896. Campinas - São Paulo-Brasil. josueps@unicamp.br

${ }^{1}$ A tradução desse e de outros textos citados aqui diretamente da língua francesa é minha. la época, que, segundo Gorz (1964), oscilava entre o reformismo social democrata, que se contentava em gerir o "neocapitalismo", e o esquerdismo, que acenava com um longínquo futuro socialista, sem se preocupar em mostrar o caminho para lá chegar. Com isso, ficava-se entre o conformismo adaptativo de um e o radicalismo inconsequente do outro, criando um impasse que só contribuía para enfraquecer e paralisar as lutas operárias em direção ao socialismo. Foi com o objetivo de superar tal impasse que Gorz se debruçou sobre o tema, principalmente nos três livros que publicou durante a década de 1960: Stratégie Ouvrière et Néocapitalisme (1964), ${ }^{2}$ Le Socialisme Difficile $(1967)^{3}$ e Réforme et Révolution (1969), ${ }^{4}$

2 Publicado no Brasil pela Zahar Editores, em 1968, como Estratégia Operária e Neocapitalismo. Doravante citado aqui como Gorz, 1968a.

${ }^{3}$ Publicado no Brasil pela Zahar Editores, também em 1968, como $O$ socialismo difícil. Doravante citado aqui como Gorz, 1968b.

${ }^{4}$ Esse livro é composto pela primeira parte de Estratégia Operária e Neocapitalismo, o terceiro capítulo de $O$ socialismo difícil, intitulado "reforma e revolução", além de um longo e importante prefácio de 46 páginas, no qual Gorz aprofunda sua análise sobre temas como necessidades, conquista do poder pela base e as funções do partido revolucionário. Esse livro não foi traduzido no Brasil (Gorz, 1969). 
cujos títulos são, aliás, bem indicativos de seu propósito de superar a suposta dicotomia entre reforma e revolução.

Esses textos serão minha fonte privilegiada para apresentar seu conceito de "reformas revolucionárias”, objeto da primeira parte do presente artigo (I). Mas, embora sua elaboração tenha se dado, como mencionei antes, na década de 1960, sua ideia de "reformas revolucionárias" está presente em textos posteriores, como procuro mostrar na segunda parte deste artigo, recorrendo a suas análises de dois temas importantes e interligados em seus escritos posteriores: a redução generalizada do tempo de trabalho e a renda social garantida (II). A escolha desses temas tem o objetivo de fundamentar a tese, anunciada acima, de que o conceito de "reformas revolucionárias" medeia toda a obra de Gorz, tornando-se uma espécie de unificador metodológico de suas formulações teóricas e políticas. Para indicar sua atualidade, procuro, em minhas considerações finais (III), fazer algumas aproximações entre o conceito gorziano de "reformas revolucionárias" e algumas formulações similares, elaboradas por outros autores contemporâneos no âmbito da teoria social crítica, ainda que, muitas vezes, as terminologias utilizadas para tanto por esses últimos não coincidam com

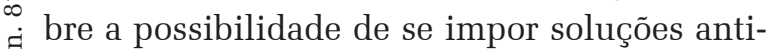

§ ${ }^{5}$ Utilizo aqui a expressão teoria social crítica num sen$>$ tido lato, que não necessariamente se confunde com a â concepção mais estrita de teoria crítica, conforme a tradição frankfurtiana. Alguns estudiosos costumam usar a expressão Teoria Crítica, com maiúsculas, para se referir Tू a essa última, enquanto utilizam minúsculas para se referir às outras tradições críticas. Eu prefiro não utilizar I esse critério por duas razões: uma é ausência de unidade Ư interna na própria tradição frankfurtiana; a outra se refere à intensa interlocução entre os autores associados a essa última e autores de outras tradicões que também se autodefinem como teóricos críticos. Ver também, a respeito: Silva (2008, p. 35-52; 2017). capitalistas no interior do próprio capitalismo, sem que tais soluções sejam logo incorporadas pelo sistema:

\begin{abstract}
Seria possível no interior do capitalismo - isto é, sem havê-lo previamente demolido - impor soluções anticapitalistas que não sejam logo incorporadas e subordinadas ao sistema? É a velha pergunta sobre 'reforma e revolução'. Era (ou é) primordial quando o movimento tinha (ou tem) escolha entre a luta por reformas ou a insurreição armada. Este não é mais o caso na Europa ocidental. Eis por que a pergunta não mais possui a forma de uma alternativa: refere-se apenas à possibilidade de 'reformas revolucionárias', isto é, reformas que se encaminham no sentido de uma transformação radical da sociedade. (Gorz, 1968a, p. 12)
\end{abstract}

Essa indagação remete, segundo Gorz (1964, p. 12), para "a velha questão sobre 'reforma e revolução", questão que orienta sua análise subsequente sobre o tema e à qual ele responde nos seguintes termos:

Não é necessariamente reformista uma reforma rei-
vindicada não em função do que é possível no qua-
dro de um sistema e de uma gestão dados, mas do
que deve ser tornado possível em função das neces-
sidades e das exigências humanas [...] O que é pró-
prio de uma luta por reformas não reformistas - por
reformas anticapitalistas - é que esta luta não faz
depender, de critérios capitalistas de racionalidade,
a validade e o direito tradicionalmente consagrado
das necessidades. Ela não se determina em função
do que pode ser, mas do que deve ser. (Gorz, 1968a,
p. 13, grifo do autor )

Antes de continuar apresentando sua análise da questão, devemos lembrar aqui que Gorz não é o primeiro autor a se preocupar com a relação entre reforma e revolução. Ainda no final do século XIX, Rosa Luxemburg, no livro intitulado Reforma, Revisionismo e Oportunismo, escrito para polemizar com os chamados revisionistas no interior da social democracia alemã de então, entre os quais se destaca Eduard Bernstein, lidou com a mesma questão. ${ }^{6}$

${ }^{6}$ Ver, a propósito, como Rosa Luxemburg inicia o prefácio de seu mencionado livro: "Pode então a social-democracia ser contra as reformas? Pode opor-se a revolução social, a transformação da ordem existente, que constitui a sua finalidade, às reformas sociais? Certamente não. A luta cotidiana pelas reformas, pela melhoria da situação do povo trabalhador no próprio quadro do regime existente, pelas instituições democráticas, constitui mesmo para a 
Mas eu não entrarei aqui nas formulações de Rosa Luxemburg. A menção a ela é apenas para, inicialmente, deixar claro que Gorz não é o primeiro a tratar do tema e, em segundo lugar, chamar a atenção para o fato de que as formulações de Gorz da década de 1960, sem esquecer os diferentes contextos em que os dois escreveram, podem também se aproximar, em alguma medida, das concepções defendidas por Rosa Luxemburg em sua época.

O que é relevante para Gorz, na distinção entre uma reforma reformista e uma reforma nãoreformista - isto é, uma reforma revolucionária e anticapitalista - são os critérios nos quais ela se baseia. Se a adoção de uma dada reforma se dá em função de critérios capitalistas de racionalidade, com objetivo de reproduzir o sistema, o qual, com o tempo, tende a acomodá-la, então tal reforma seria facilmente classificada como reformista. Mas, ao contrário, se a reforma é resultado de uma luta para impor limites à racionalidade capitalista e se baseia em critérios de prioridade social e humana, então se trata de uma reforma anticapitalista e, portanto, revolucionária. Ao opor os dois tipos de reformas, Gorz se refere a ambas a partir de duas estratégias. Uma denominada "reformismo neocapitalista”, associado às chamadas reformas reformistas, que são concebidas para melhor gerir o capitalismo, tendência que Gorz identificava com a social democracia europeia de então. A outra estratégia, a de reformas revolucionárias, ele definia como socialista.

A estratégia socialista de reformas que ele propunha partia, inicialmente, de um diagnóstico da nova situação - o neocapitalismo -, na qual não seria mais possível imaginar a pertinência da antiga estratégia inspirada na ideia de que a classe operária nada tinha a perder além de seus grilhões. Nessa nova situação, segundo Gorz (1964), o capitalismo teria con-

social-democracia, o único meio de travar a luta de classe proletária e trabalhar no sentido da sua finalidade, isto é, a luta pela conquista do poder político e supressão do assalariato. Existe para a social-democracia um laço indissolúvel entre as reformas sociais e a revolução, sendo a luta pelas reformas o meio, mas a revolução social o fim." (Luxemburg, 1970, p. 7). seguido acomodar muitas das reivindicações do movimento operário, propiciando-lhe, pela inserção na sociedade de consumo, condições de vida bem diferentes daquela condição de miséria material vivenciada pelos trabalhadores do início da revolução industrial. Gorz considerava, então, que apenas uma pequena parte, cerca de $1 / 4$, da população trabalhadora dos países centrais do capitalismo, ainda vivia excluída do mercado de consumo e era, ademais, constituída basicamente por setores marginalizados, cuja posição no processo produtivo não permitia que se a considerasse um sujeito relevante de transformação social anticapitalista (Howard, 1972; Münster, 2008; Rodrigues, 2009; Silva, 2011).

Em tal situação não daria mais para derivar uma estratégia de transformação anticapitalista apenas da urgência em satisfazer as necessidades vitais do proletariado, pois essas já tinham, em grande medida, sido atendidas pelo neocapitalismo europeu e norte-americano. Assim, a luta pela transformação socialista impunha a elaboração de uma estratégia nova, ancorada nas novas necessidades qualitativas, que faziam parte dos anseios dessa "nova classe operária”, mais qualificada e mais exigente.

Por isso, ele também considerava pertinente elaborar mais em torno da categoria necessidade, que estava, na verdade, na base de toda sua análise da nova situação. Partindo, então, da formulação de Marx (apud Gorz, 1969, p. 14), segundo a qual "o homem é um ser histórico cujas faculdades e necessidades se desenvolvem sem que seja possível assinalar a esse desenvolvimento um limite", Gorz (1969, p. 14) afirma que "da mesma forma que as modalidades da produção e da reprodução da vida, as necessidades são sempre socialmente e historicamente determinadas. E isto, mesmo que se trate de necessidades biológicas” . Por essa razão, em vez de distinguir entre necessidades vitais e necessidades históricas, ele prefere, conforme o texto citado a seguir, a distinção entre necessidades e exigências: 
Nós reservamos o termo necessidade (besoin) aos fins, cuja busca está diretamente ligada à produção e à reprodução da vida. Por 'exigências' (exigences), em revanche, nós designaremos os fins que os indivíduos perseguem não mais sob o império da 'necessidade natural', mas por seu próprio movimento, em vista da realização autônoma de suas faculdades intelectuais, artísticas, afetivas, criativas [...]. Exigências são necessidades adquiridas, históricas, que se desenvolvem correlativamente às faculdades intelectuais, artísticas, criativas e exigem imperiosamente poder se realizar pela produção de objetos que as confirmem. (Gorz, 1969, p. 14-15, grifo do autor) ${ }^{7}$

Portanto, para sensibilizar os trabalhadores qualificados daqueles países para a luta revolucionária. não bastava apelar para reivindicações de natureza quantitativa, como aumento de salário e redução da jornada de trabalho; precisava-se, além disso, saber quais os seus anseios e desejos de natureza existencial que o neocapitalismo não seria capaz de atender. Era, assim, da insatisfação manifesta nas

${ }^{7}$ Ao escrever sobre as novas necessidades ou exigências, Gorz remete ao texto da médica e militante comunista italiana Laura Conti, "Les conditions de dévelopment culturel en Union Soviétique”, publicado na revista Les Temps Modernes, em outubro de 1963. Em seu texto, Conti analisa as condições de desenvolvimento cultural na então União Soviética, comparando, primeiro, o desenvolvimento da cultura artística, literatura e pintura, ao desenvolvimento da ciência naquele país, para concluir que o desenvolvimento das primeiras era bem mais lento que da segunda. Em segundo lugar, para aprofundar sua compreensão do problema, ela compara os dois desenvolvimentos na União Soviética com os respectivos desenvolvimentos nos países $\wedge$ capitalistas. Sua conclusão, nessa segunda comparação, era

de que, nos países capitalistas, ocorria o inverso: as artes se

ㄱ desenvolviam mais rapidamente que as ciências. Para fazer

$\dot{\sim}$ esse tipo de análise, ela recorre ao conceito marxiano de necessidades, contrapondo as necessidades fundamentais às necessidades históricas, para derivar, daí, o conceito de ๖ necessidades histórico-fundamentais. Esse último resulta

$\therefore$ da historização das necessidades fundamentais decorrente

$\stackrel{\sim}{\sim}$ do progresso social. Daí ela falar em três tipos de necessi-

I. dades, vitais (ou fundamentais), históricas e histórico-fun-

○ิ damentais, essa última significando necessidades históricas เ que se tornaram fundamentais (Conti, 1963). Ao se referir

2. ao texto de Conti, Gorz não o comenta; mas, ao preferir a

$\rightarrow$ distinção entre necessidades e exigências, em vez de dis-

$\therefore$ tinguir entre necessidades fundamentais e necessidades

- históricas, ele parece querer se diferenciar da interpreta-

§ ção da autora italiana, pelo menos em nuance, realçando

$>$ que as chamadas necessidades fundamentais também são,

ê em algum sentido, históricas (Gorz, 1969). Por outro lado,

- creio que estes comentários esclarecem também a dúvida

$\stackrel{\pi}{\geq}$ de Willy Gianinazzi (2016, p. 77), quando se refere ao fato

๙ de eu não distinguir, em meu livro sobre Gorz (Silva, 2011),

- entre besoin e necessité. Embora não tenhamos, de fato, na

Iíngua portuguesa, uma palavra com a mesma rica polisse-

$\checkmark$ mia da francesa besoin ou da inglesa need, atribuo ao fato

- de meu texto ter sido escrito originalmente em inglês, onde

se traduz normalmente besoin por need. Ao vertê-lo para o

português, eu simplesmente traduzi need por necessidade,

$\circlearrowleft$ sem me preocupar em esclarecer tais nuances. diversas mobilizações da nova classe operária com a divisão capitalista do trabalho, com a separação entre concepção e execução das atividades, com o controle capitalista do processo de trabalho, enfim, com a condição de alienação no trabalho que se devia partir para elaborar uma nova estratégia de transformação anticapitalista. Tratava-se, pois, de uma estratégia que deveria ser capaz de ligar as demandas cotidianas mais elementares dos trabalhadores com as reivindicações mais abrangentes, de prazo mais longo, em direção ao socialismo. Daí serem elas reformas não reformistas, ou reformas revolucionárias, que desafiavam a velha dicotomia entre reforma e revolução.

Mas, para elas não serem reabsorvidas pelo sistema, isto é, para serem efetivamente revolucionárias, afirma Gorz (1968a, p.14),

tais reformas supõem uma modificação do relacionamento das forças; supõem que os trabalhadores conquistem poderes [...] suficientes para abrir, para conservar abertas e para ampliar no seio do sistema das orientações existentes um número suficiente de brechas que abalem o capitalismo em seus suportes. Supõem reformas de estruturas. ${ }^{8}$

Ao considerar, por outro lado, que existia o risco de esses poderes serem absorvidos e subordinados pelo capitalismo, Gorz (1968a, 13-14) afirma que "a subordinação não é inevitável”, questão que o leva a formular também sobre a categoria poder, distinguindo entre poder subalterno e poder autônomo.

Ele chama de poder subalterno

a associação ou a participação dos trabalhadores em uma política e uma gestão econômica que os induzem a dividir a responsabilidade no nível dos resultados e da execução, interditando-os simultaneamente a se envolverem com as decisões e critérios em virtude dos quais essa política e essa gestão foram decididas. (Gorz, 1968a, 15, grifo do autor ).

Trata-se, nesse caso, de uma situação na

${ }^{8}$ Gorz (1968a, p. 14, grifo do autor) também procura deixar claro o que ele entende por reformas de estrutura: "A reforma de estrutura é, por definição, uma reforma aplicada ou controlada por aqueles que a reclamam. Quer seja agrária, universitária, imobiliária, regional, administrativa, econômica, etc., a reforma de estrutura comporta sempre o nascimento de novos centros de poder democráticos." 
qual os trabalhadores podem participar da execução de uma política, sem, no entanto, participarem na elaboração das premissas que a fundamentam e das quais são apenas cúmplices.

Bem diferente, no entanto, é o caso do poder autônomo, que Gorz assim define:

O poder dos trabalhadores de colocar em causa, através dos efeitos das modalidades de execução as próprias premissas de uma política e de uma gestão; de colocá-las em causa, mesmo por antecipação, graças ao poder de controle sobre todos os dados em virtude dos quais a política de gestão é elaborada. Semelhante poder autônomo constitui um primeiro passo para a subordinação das exigências da produção às exigências humanas, tendo como última perspectiva a conquista do poder de autogestão. (Gorz, 1968a, 15, grifo nosso) ${ }^{9}$

Mas essa concepção de poder autônomo, Gorz (1968a, p. 15) acrescenta, "não pode limitar-se à contestação meramente negativa”. Numa estratégia socialista de reformas, portanto, a alternativa está entre essas duas formas de poder. E somente partindo do poder autônomo seria possível alcançar a hegemonia da classe trabalhadora, do sujeito revolucionário. Assim, ele concluía, que "o que precisamente diferencia uma reforma de espírito reformista de uma reforma de espírito não reformista é a questão do poder operário” (Gorz, 1968a, p. 40). Todo esse processo requer, ainda, além do controle do processo de trabalho na fábrica, mediações outras que incluem o sindicato e o partido revolucionário (Gorz, 1968b, 1969). Enfim, como ele mesmo sintetiza:

Na prática, o que distingue uma estratégia socialista de reformas de um reformismo neocapitalista de tipo socialdemocrata é menos cada uma das reformas preconizadas e mais cada um dos objetivos programáticos, ou seja: $1^{\circ}$ a presença ou ausência de vínculos orgânicos entre as diversas reformas; $2^{\circ}$ a cadência e as modalidades de sua execução; $3^{\circ}$ a vontade ou ausência de vontade de colocar em prática novas ações de ruptura do equilíbrio provocado pelas primeiras ações reformadoras. (Gorz, 1967, p. 75).

Como se pode ver, a estratégia socialista

${ }^{9}$ Tradução modificada. de reformas assentava-se no controle do processo produtivo pelo sujeito revolucionário - o proletariado - que, organizado em sindicatos e no partido revolucionário, encabeçaria o processo de transformação social em direção ao socialismo. ${ }^{10}$

Durante as décadas de 1970 e 1980, no entanto, importantes pressupostos dessa estratégia mudaram em decorrência, principalmente, da análise que ele faz da nova situação, marcada pelo desemprego em massa, provocado, em grande medida, pelas mudanças tecnológicas poupadoras de trabalho, o que ele chamou de revolução microeletrônica. Essa última, segundo Gorz (1983, p. 73) , “deve ser compreendida num duplo sentido: a) a quantidade de trabalho necessário decresce até se tornar marginal na maior parte das produções materiais e das atividades de organização; b) o trabalho não implica mais um face a face do trabalhador com a matéria".

Assim, sobretudo a partir de 1977, o conjunto de textos que Gorz publicou indica um novo diagnóstico de época que o leva a rever várias de suas posições anteriores. Seu livro Adieux au prolétariat, ${ }^{11}$ de 1980, talvez seja o melhor indicador das mudanças em suas formulações teóricas e políticas . Além do significativo "adeus ao proletariado”, que dá título ao livro - que causou "frisson" entre os marxistas mais ortodoxos -, chama a atenção, no livro, o uso de expressões como títulos de capítulos: "a impossível apropriação coletiva"; "o proletariado como decalque do capital”; "poder operário?”; e assim por diante. E isso deve, provavelmente, ter provocado algum efeito em sua concepção de reformas revolucionárias. É o que veremos a seguir.

\section{REDUÇÃO DO TEMPO DE TRABA- LHO E RENDA SOCIAL GARANTIDA}

Na década de 1960, durante a elaboração do conceito de reformas revolucionárias, Gorz considerava as lutas pela redução do tem-

${ }^{10}$ Para uma leitura diferente da que empreendo aqui, ver Amorim (2009)

${ }^{11}$ Adeus ao proletariado. 
po de trabalho e por aumento de salários como reivindicações de natureza quantitativa (Gorz, 1969). ${ }^{12}$ Se a estratégia socialista de reformas de então estava fundamentada basicamente em reivindicações de natureza qualitativa, decorrentes das novas necessidades históricas e existenciais, as mencionadas reivindicações quantitativas tinham, no máximo, um lugar secundário no conjunto de tal estratégia de reformas não reformistas, da mesma forma que elas pouco contribuiriam para afirmar o poder autônomo da classe operária, uma vez que podiam ser perfeitamente assimiladas pelo neocapitalismo e seu modelo de consumo. ${ }^{13}$ Portanto, considerando que "as necessidades coletivas encontravam-se [...] objetivamente em contradição com a lógica do desenvolvimento capitalista”, a estratégia socialista de reformas devia comportar a contestação radical do sistema nos âmbitos "econômico, político e cultural” (Gorz, 1968a, p. 101).

Mas, como já escrevi antes, a situação mudou; e também mudou a posição de Gorz a respeito da redução do tempo de trabalho. A primeira manifestação dessa mudança de posição em relação ao tema da redução do tempo de trabalho aparece em seu livro de 1977, Écologie et Liberté, assinado Michel Bosquet, pseudônimo mais utilizado como jornalista e nos escritos ^ sobre ecologia, mas trazendo André Gorz entre

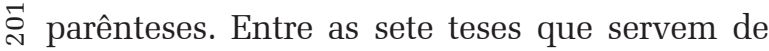
๗ conclusão ao livro, no qual ele também fala, pela primeira vez, em utopia dualista - formada ๘

今ิ 12 Para uma visão mais geral sobre "tempo individual e เ tempo social” na obra de Gorz, ver Silva (2009).

- ${ }^{13}$ Em suas palavras, "não é mais no nível das únicas neces$\stackrel{-}{\infty}$ sidades de consumo que se situa a linha de rotura revolu¿ cionária entre as classes", porque o capitalismo moderno ○ "pode reassimilar tanto os aumentos nominais de salários

m. quanto as reduções de horário, sem que os lucros ou, so-

$>$ bretudo, o poder dos monopólios sejam atingidos, sem

¿ิ que a classe operária, através de vitórias reivindicativas,

శ్త aumentem coisa alguma seu poder" (Gorz, 1968a, p. 31).

즌 14 A utopia dualista, formada pelas esferas das atividades autônomas e a esfera das atividades heterônomas, inspira-se claramente no Marx do (1967, p. 814-831) terceiro

volume de $O$ Capital, onde esse último fala em reino da li-

$\wp$ berdade e reino da necessidade. Gorz desenvolve sua con-

cepção de sociedade dualista nos livros Adieux au prolé-

tariat (Adeus ao proletariado, 1980), e Métamorphoses du

ษ travail: Quête du Sens (Metamorfoses do trabalho,1988). a sexta tese inicia-se assim: "Estando o trabalho social limitado às produções socialmente necessárias, a redução do tempo de trabalho poderá caminhar junto com a expansão das atividades autônomas e livres" (Gorz, 1977, p. 94). Desde então, em seus quatro livros subsequentes, o tema da redução do tempo de trabalho passa a ser um objeto central de suas teorizações (Gorz, 1980, 1983, 1988, 1991).

O texto a seguir, de Adieux au prolétariat , talvez seja o que manifesta de forma mais clara essa mudança de posição em relação à importância da redução do tempo de trabalho em suas formulações: "O mesmo trabalho que [...] é corveia quando realizado cotidianamente e em tempo integral, torna-se um tempo entre outros quando, repartido para a população inteira, é realizado em apenas quinze minutos por dia." (Gorz, 1980, p. 146). O trabalho, mesmo sendo heterodeterminado, deixaria de ser "corveia" se sua duração ocupasse apenas um tempo residual na vida dos indivíduos; então, a almejada autonomia poderia também ser alcançada fora da esfera do trabalho, no tempo livre tornado predominante. Como se vê, essa posição é bem diferente daquela que Gorz sustentava na década de 1960, quando depositava sua esperança de transformação social no poder autônomo da classe operária, assim como na apropriação coletiva do processo produtivo pelo proletariado.

Na avaliação de Gorz, essa apropriação coletiva tornou-se agora impossível, seja devido à complexidade dos aparelhos produtivos e de gestão (Gorz, 1980), seja pelos efeitos da chamada revolução microeletrônica que aboliria o trabalho (Gorz, 1983). É esse o contexto no qual ganha sentido uma política de redução generalizada do tempo de trabalho, tema de muitos debates nas décadas de 1980 e 1990, da qual Gorz é um dos principais proponentes. Na verdade, para Gorz e também para muitos outros autores, a redução do tempo de trabalho necessário era, então, uma evidência e decorria, em grande medida, do aumento de produtividade permitido pelas transformações tec- 
nológicas e pelas novas políticas de gestão. ${ }^{15}$

Como teórico crítico, Gorz procurava contrapor-se à tendência em curso, na qual o Capital se apropriava dos ganhos de produtividade, deixando aos trabalhadores reais ou potenciais todo o prejuízo das rápidas transformações, traduzido em desemprego em massa. Daí a necessidade de uma estratégia (nova) que permitisse distribuir os ganhos de produtividade para toda a sociedade. E essa estratégia passava pela redução planejada do tempo de trabalho, o que, para Gorz, era a única saída para evitar a dualização da sociedade entre o grupo cada vez menor de empregados permanentes em tempo integral e a crescente massa de desempregados, subempregados e trabalhadores em tempo parcial (Gorz, 1983, 1988, 1991). Na visão de Gorz, uma redução substancial do tempo de trabalho transformaria o trabalho em apenas uma atividade entre outras e contribuiria para solapar as relações de dominação baseadas na ética produtivista do trabalho, partilhada pela direita e pela esquerda ortodoxa (Gorz, 1988). Por outro lado, ele também estava ciente de que sua crítica convergia com os resultados de algumas pesquisas recentes que indicavam a crescente desafeição de setores mais jovens da população francesa em relação ao trabalho assalariado como fonte de identidade social (Adret, 1977; Rousselet, 1974; Schehr, 1999).

Embora tivesse ciência do crescente número de autores que viam, na redução do tempo de trabalho, uma possível saída para o desemprego em massa, Gorz sabia também que a maneira como colocar em prática tal política era objeto de importantes controvérsias, não só entre os proponentes da esquerda, mas também entre esquerda e direita. Por isso, ele procurou delinear resumidamente os cinco pontos que considerava polêmicos numa polí-

${ }^{15}$ O debate sobre tempo de trabalho na França durante as décadas de 1980 e 1990 é muito amplo e já tratei dele em outros lugares (Silva, 1996, 2011). Aqui, refiro-me apenas a dois livros que considero simbolicamente importantes para aquele debate: Travailler deux heures par jour, do coletivo Adret (1977), e La révolution du temps choisi, de Jacques Delors (1980). tica de redução do tempo de trabalho:

Conforme a forma adotada, a redução do tempo de trabalho pode, com efeito, reduzir as desigualdades ou aumentá-las; aumentar a insegurança ou a seguridade; ser um fator de inserção ou de exclusão social. Ela pode ser: 1) igual para todos ou diferenciada; 2) geral ou seletiva; 3) calculada à escala da semana, do ano ou da vida; 4) ser acompanhada de aumento, de manutenção ou de redução da renda; 5) romper, abrandar ou manter o elo entre direito ao trabalho e direito à renda. Suas modalidades implicam escolhas fundamentais de sociedade. (Gorz, 1988, p. 232-233, grifo nosso)

Após delineá-los, Gorz aprofunda a análise desses pontos tanto em seu livro Métamorphoses du travail: Quête du Sens, de 1988, quanto no livro seguinte Capitalisme, Socialisme, Ecologie: Désorientations, Orientations, de 1991, que tem um capítulo dedicado à elaboração do que ele intitula "a redução do tempo de trabalho como contrato social”, no qual apresenta, de forma elaborada, os contornos de sua proposta (Gorz, 1991, p. 185-214; Silva, 2011, p. 174-184).

Ainda no que se refere aos cinco pontos da citação acima, a posição de Gorz em relação aos três primeiros é bastante clara: a redução do tempo de trabalho deve ser igual para todos, ela deve ser geral e calculada com uma escala que possibilite maior autonomia aos indivíduos nos seus planos de vida. Já no tocante aos pontos quatro e cinco, a questão é um pouco mais complexa porque envolve também o segundo tema a ser discutido nesta parte do artigo: a renda social garantida. É dela que trato a seguir.

$* * *$
Gorz começa a discutir o tema da renda social garantida ainda no início da década de 1980, num artigo escrito em dezembro daquele ano e denominado "Nove teses para uma esquerda futura” (Gorz, 1981). Ali encontramos sua primeira menção à renda social, que ele discute já em conexão com sua proposta de redução do tempo de trabalho. No mencionado 
artigo, logo transformado em prefácio à segunda edição de Adieux au prolétariat , ele assim se expressa a respeito do tema:

A gestão social da abolição do trabalho supõe que se
ponha fim à confusão que sob a influência do keyne-
sianismo se instalou entre 'direito ao trabalho' e $1^{\circ}$.
direito a um emprego assalariado; $2^{\circ}$. direito a uma
renda; $3^{\circ}$. direito à criação de valores de uso; $4^{\circ}$. di-
reito de acesso aos instrumentos que permitem criar
os valores de uso. (Gorz, 1981, p. 1544 , grifo nosso)

Desde então, nos três livros publicados a seguir, ele desenvolve a análise sobre a renda social garantida (Gorz, 1983, 1988, 1991). Mais precisamente, ele concebia a renda social garantida como uma forma de financiar a redução do tempo de trabalho. Ou seja, a renda social garantida, na forma de um "segundo cheque", permitiria que se reduzisse o tempo de trabalho sem redução de salário. ${ }^{16}$ Entretanto, para ele, a renda social garantida devia manter o vínculo com o trabalho socialmente necessário, mesmo que esse último fosse exercido em curta duração. O texto citado a seguir exemplifica bem o que ele pensava a respeito:

Não é, portanto, a garantia de uma renda independente de todo trabalho que se encontrará no centro de um projeto de esquerda, mas o vínculo indissolúvel entre direito à renda e direito ao trabalho. Cada cidadão deve ter o direito a um nível de vida normal; mas cada um e cada uma deve também ter a possiऽे bilidade (o direito e o dever) de fornecer à sociedade i o equivalente-trabalho do que ele ou ela consome: o

${ }^{17}$ Ver também, sobre o direito ao trabalho como um direito político, Gorz (1992, 1994).
É somente a partir de 1997, com o livro Misérias do presente, riqueza do possível, que ele revê sua posição a respeito do tema e adere à tese da desvinculação entre renda e trabalho, conforme suas próprias palavras: "por muito tempo, recusei a ideia de uma renda social que permita 'viver sem trabalhar'” (Gorz, 1997, p. 139). ${ }^{18}$ No quarto capítulo desse livro, intitulado "Sair da sociedade salarial", ele apresenta quatro razões para justificar sua mudança de posição, aderindo à ideia de incondicionalidade da renda social. Resumidamente, elas se referem, em primeiro lugar, à emergência do imaterial, objeto de seu livro seguinte, escrevendo que "quando a inteligência e a imaginação (general intellect) tornam-se a principal força produtiva, o tempo de trabalho deixa de ser a medida do trabalho." (Gorz, 1997, p. 140), o qual deixa de ser mensurável. O segundo argumento é a defesa de uma incondicionalidade capaz de fortalecer o vínculo social. Em terceiro lugar, a alocação universal da renda é, para ele, a proposta que melhor se adapta às condições de uma economia na qual o conhecimento se torna a força produtiva principal. Por fim, ela é também a que melhor responde à situação de uma economia na qual a crescente produtividade do trabalho se traduz em crescente excedente da força de trabalho. ${ }^{19}$

Em síntese, ele assim resume sua nova posição:

Uma das funções da alocação universal é [...] fazer do direito ao desenvolvimento das faculdades de cada um o direito incondicional a uma autonomia que transcende sua função produtiva e existe por e para ela mesma no plano moral (autonomia de julgamento de valor), político (autonomia da decisão concernente ao bem comum), cultural (invenção de estilos de vida, modelos de consumo e arte de viver), existencial (capacidade de cuidar de si, em vez de abandonar aos especialistas e autoridades o

${ }^{18}$ Para uma análise mais detalhada dessa mudança de posição, ver: Silva (2011, p. 174-184, 2014a, p. 63-83); para uma boa síntese em português da abordagem de Gorz sobre o conceito de trabalho, ver Langer, 2004.

${ }^{19}$ Sobre sua abordagem a respeito do imaterial, ver Silva (2014c). Ainda em relação ao debate sobre o imaterial, vale confrontar duas outras leituras: Amorim, (2009) e Camargo (2011). 
cuidado de decidir o que é bom para cada um de nós). (Gorz, 1997, p. 145) ${ }^{20}$

No mesmo livro, Gorz também delineia os contornos do que seria uma sociedade de multiatividade e aponta os caminhos possíveis para sair da sociedade do trabalho assalariado. Assim, no mesmo espírito das reformas revolucionárias preconizadas por ele na década de 1960, ele propõe o seguinte conjunto articulado de políticas específicas que permitiria:

1. garantir a todos uma renda incondicional e suficiente;

2. redistribuir o trabalho e liberar o tempo, de modo a facilitar o controle individual e coletivo sobre o tempo;

3. favorecer o florescimento de novas sociabilidades e formas de cooperação e de troca que reforcem os vínculos sociais (Gorz, 1997, p. 121-178).

Na base dessas propostas há um fio condutor, anunciado pelo título "Sair da sociedade salarial" que ele dá ao quarto capítulo de seu livro Misères du présent: Richesse du possible ${ }^{21}$ de 1997. ${ }^{22}$ Para sair da sociedade salarial, isto é, do capitalismo, é preciso, segundo Gorz, aprofundar-se na análise crítica das categorias que lhe dão fundamento: a forma mercadoria e a chamada lei do valor (Silva, 2014c).

Esse é o sentido de sua crítica da racionalidade econômica, elaborada principalmente no livro Metamorfoses do trabalho de 1988, mas que é o verdadeiro pano de fundo de suas discussões a respeito tanto do tempo de trabalho, a partir de 1977, como da renda

${ }^{20}$ Uma contraposição do texto que acabo de citar com o de Metamorfoses do trabalho, já citado na página anterior, deixa clara a referida mudança de posição a respeito do vínculo (ou não) entre trabalho e renda.

${ }^{21}$ Misérias do presente. Riqueza do possível.

${ }^{22}$ Vale lembrar que, dez anos depois, em 2007, após um intenso intercâmbio intelectual com os textos de alguns autores vinculados à chamada "nova crítica do valor", principalmente Robert Kurz e Moishe Postone, Gorz escreve dois outros textos, os últimos que publicou em vida, com títulos ainda mais sugestivos: "Crise, decrescimento e saída do capitalismo" (Gorz, 2010, p. 67-76), e "A saída do capitalismo já começou" (Gorz, 2010, p. 25-42). Willy Gianinazzi considera o último dos dois o mais kurziano texto de Gorz (Gianinazzi, 2016, p. 331-335). Para a relação de Gorz com as formulações daqueles autores, ver também Machado (2016). social garantida, a partir de 1981. Nos dois casos, mesmo considerando suas mudanças de posição ao longo dos anos, a crítica radical às categorias capitalistas é a tônica de seus diagnósticos de época.

\section{CONSIDERAÇÕES FINAIS}

Conforme prometi no início deste artigo, devo tratar agora de outros autores cujas formulações permitem estabelecer pontes com o conceito de reformas revolucionárias de Gorz. Entre os diversos autores, cujas formulações poderiam se aproximar das de Gorz, decidi me limitar, por economia de espaço, aos cinco que me pareceram mais apropriados.

Começo com Claus Offe, que tem se debruçado sobre vários temas semelhantes aos que ocupam a reflexão de Gorz. A propósito, vejo muita afinidade nas análises críticas de André Gorz e de Claus Offe a respeito dos seguintes temas: crítica do trabalho sob o capitalismo, diagnóstico sobre a irreversibilidade do desemprego, proposição de reduzir o tempo de trabalho, apoio a alguma versão de renda social garantida, apoio a atividades que escapam à lógica da mercadoria e defesa da ecologia política. Assim, embora haja muitas diferenças tanto em suas trajetórias profissionais (Gorz foi jornalista e filósofo autodidata, Offe seguiu uma carreira acadêmica como professor universitário e pesquisador) como entre o marxismo existencialista de Gorz e o marxismo analítico de Offe, eles partilharam, durante as décadas de 1980 e 1990 pelo menos, importantes afinidades nas análises sobre os temas acima. Por outro lado, mesmo Offe não utilizando a terminologia de Gorz no que diz respeito às reformas revolucionárias, percebe-se que há muito em comum quando se olha o conteúdo das proposições dos dois (Offe, 1984, 1985, 1995; Offe e Heinze, 1992). A propósito, o conjunto de medidas de política social - redução do tempo de trabalho, instituição de uma renda básica universal e incentivo aos chama- 
dos círculos cooperativos - proposto por Offe, sobretudo no texto de 1995, intitulado "Full Employment: Asking The Wrong Question?" (1995), é muito parecido com as propostas formuladas por Gorz no livro Misères du présent: Richesse du possible, de 1997 e já citadas: redução do tempo de trabalho, alocação universal de uma renda de existência sem vínculo com o trabalho e o incentivo às chamadas atividades autônomas. Isso é, a meu ver, suficiente para mostrar a semelhança de ambos nas abordagens de alguns importantes temas contemporâneos (ver também Silva, 2008).

Embora em escala menor que no caso de Offe, o também marxista analítico Eric Olin Wright é outro autor cujas proposições partilham, em grande medida, o mesmo conteúdo das proposições de Gorz (Wright, 2006a; 2006b). Isso pode ser dito pelo menos em relação a temas como socialismo e renda básica, que, tratados conjuntamente, sugerem a mesma dinâmica de mudança social anticapitalista que a concepção gorziana de reformas revolucionárias. Foi também Wright que alertou Nancy Fraser (2003, p. 108, nota. 91) a respeito da origem gorziana da expressão via média de "reformas revolucionárias", que utiliza em alguns de seus escritos, conforme ela mesma reconhece em um de seus textos. De toda for$\checkmark$ ma, penso que eles, Wright e Gorz, se aproxi-

${ }^{23}$ Mouvement Anti-Utilitariste en Science Social (movimento antiutilitarista nas ciências sociais). Em relação à proximidade entre as formulações de Gorz e de Caillé, vale conferir o artigo do último: "Au-delà du marxisme et du capitalisme" (Caillé, 2013), no qual ele analisa criticamente as ideias de Gorz. um dos principais teóricos. ${ }^{24}$ Aliás, é o próprio Gorz, em seu livro de 1997, que reivindica tal aproximação, quando justifica sua adesão à incondicionalidade da renda de existência, referindo-se à ideia de "incondicionalidade forte" defendida por Caillé (Gorz, 1997, p. 144).

Mas é Nancy Fraser quem utiliza explicitamente a expressão "via média de reformas não reformistas”, quando delineia os contornos de sua teoria da justiça em debate com Axel Honneth (Fraser, 2003: 79). E, ainda que, na ocasião, não tenha se referido a Gorz, o primeiro exemplo que ela dá de uma reforma não reformista é a renda básica incondicional. Ademais, em seu texto "From Redistribution to Recognition? Dilemmas of Justice in a 'Post-Socialist' Age" (Fraser, 1995), mesmo não falando explicitamente em reformas não reformistas, ela apresenta um modelo bidimensional de justiça cuja dinâmica de mudanças sociais se encaixa claramente no perfil das chamadas reformas revolucionárias.

A propósito, ela elabora um modelo analítico que é bem ilustrativo. O modelo, na forma de um quadro, é articulado em torno das palavras-chave Redistribuição e Reconhecimento, dispostas em linhas e contrapostas a outras duas palavras, Afirmação e Transformação, dispostas como colunas. Com isso, temos uma matriz cujos intercruzamentos entre linhas e colunas permitem-lhe classificar as políticas de redistribuição e de reconhecimento como afirmativas ou transformativas, exemplificando-as com situações reais. Assim, na primeira linha, onde cruzam Redistribuição e Afirmação, ela põe o Estado de bem-estar liberal, enquanto no cruzamento de Redistribuição com Transformação, situa o Socialismo; na segunda linha, no cruzamento de Reconhecimento com Afirmação, situa-se o Multiculturalismo dominante, e, quando Reconhecimento cruza com Transformação, temos Desconstrução. A análise do quadro deixa claro que reconhecimen-

${ }^{24}$ Já discuti, em outro texto, as teorias de Alain Caillé, de Nancy Fraser, de Boaventura de Sousa Santos, assim como de Axel Honneth, em termos do conceito gorziano de reformas revolucionárias (Silva, 2017). 
to e redistribuição, quando concebidos como políticas afirmativas, identificadas com o Estado de bem estar liberal e o multiculturalismo dominante, podem ser facilmente concebidas como reformas reformistas; mas, se ambos são avaliados pelo prisma da transformação, resultando em socialismo e desconstrução, as políticas de reconhecimento e de redistribuição podem ser facilmente identificadas com as reformas não reformistas ou revolucionárias. No primeiro caso, temos políticas compensatórias que não mexem nas estruturas de dominação ou exploração; no segundo, entretanto, temos políticas que visam a mudanças radicais na situação vigente (Fraser, 1995). ${ }^{25}$

Outro traço das formulações de Fraser (1989) que guarda proximidade com as de Gorz diz repeito ao tema das necessidades, do qual ela se ocupa já em seu primeiro livro, Unruly Practices, em especial no último capítulo, intitulado "Struggle over Needs: Outline of a Socialist-Feminist Critical Theory of Late Capitalist Culture" (1989, p. 161-187). Porém, diferentemente de Gorz, que formula suas proposições de estratégia operária com base no conceito de novas necessidades, o objetivo de Fraser é criticar a imposição de necessidades pré-definidas pelos formuladores de políticas públicas, sem que o entendimento do que são as necessidades tenha sido objeto de debate democrático com os afetados por tais políticas. Ademais, como teórica do feminismo, desigualdade de gênero é um tema central em sua produção teórica e política, enquanto ele aparece apenas de forma tangencial nas formulações de Gorz.

Boaventura de Sousa Santos, autor cujas formulações parecem-me as que mais se aproximam da ideia gorziana de reformas revolucionárias, também introduz um tema que, embora não seja estranho às preocupações de Gorz, não ocupa o centro de suas reflexões: o colonialismo. Da mesma forma que Gorz, San-

25 Ver, anteriormente, na nota de rodapé número ${ }^{9}$, onde Gorz escreve sobre reformas de estrutura, como, nesse quesito, há semelhança entre os dois autores. tos (2006, p. 420-422) também critica a clivagem entre reforma e revolução presente na história da esquerda europeia. Mas esse não é um tema central de suas formulações teóricas e políticas. Suas formulações giram, na verdade, em torno da crítica ao eurocentrismo e ao colonialismo.

Proponente de uma Epistemologia do Sul, centrada em ecologias como contraponto ao cânone da ciência moderna, Santos (2000) desenvolve uma ácida crítica ao que ele denomina "razão indolente", que seria característica da ciência ocidental moderna. A razão indolente, segundo Santos, é formada basicamente por dois subtipos: a razão metonímica, que toma a parte pelo todo, promovendo, com isso, o desperdício de experiências, enquanto a razão proléptica, o outro subtipo, assenta-se numa restrita concepção de tempo linear, que contrai o presente e expande indefinidamente o futuro. Em outras palavras, enquanto a primeira é responsável por um universalismo abstrato, que ignora o que se faz fora do mundo europeu e norte-americano, incluindo aí as formas não oficialmente científicas de saber, a segunda alimenta uma ideia de progresso que amarra o resto do mundo aos valores dominantes dos centros hegemônicos do capitalismo.

Em contrapartida, sua Epistemologia do Sul é formada por uma sociologia das ausências, que faz emergir as experiências silenciadas, e uma sociologia das emergências, que procura despertar a consciência emancipatória, ampliando o presente e contraindo o futuro, de forma a despertar as subjetividades rebeldes. Trabalhando para ampliar o presente e identificar o potencial emancipatório das lutas cotidianas, a sociologia das emergências pretende contribuir para o desenvolvimento de subjetividades rebeldes presentes nos movimentos sociais. Mas, para o bem ou para o mal, os movimentos sociais não constituem um sujeito unitário ou macrossujeito à maneira do proletariado ao qual Gorz se dirigia na década de 1960. Tampouco se pode atribuir a eles a missão histórica de instaurar o socialis- 
mo como se atribuía anteriormente ao proletariado. Aliás, esses movimentos sociais, muitas vezes, nem mesmo partilham uma pauta comum de reivindicações. Santos (2006) acredita, porém, que, cada um à sua maneira, eles lutam por emancipação, ou, mais propriamente, por emancipações, já que o entendimento do que é emancipação pode diferir de um movimento social a outro. Por isso mesmo, a sociologia das ausências e a das emergências precisam ser completadas pelo que ele denomina trabalho de tradução, que, segundo Santos (2006) e Silva (2014b), é a forma de construir interinteligibilidade entre os diversos movimentos

É com base nessa Epistemologia do Sul que Santos (2016) desenvolve sua crítica do capitalismo contemporâneo, ou neoliberalismo, que aponta, fundamentalmente, em três direções: democratização, desmercantilização e descolonização. As críticas do colonialismo, da mercantilização desenfreada e da democracia representativa existente são, portanto, objetos privilegiados de suas análises e propostas para a esquerda contemporânea, exemplificada pelo Fórum Social Mundial de Porto Alegre, que é, para Santos $(2005,2006)$, um importante lócus articulador e sujeito possível de uma globalização contra-hegemônica. Assim, ele também se coloca entre os autores que priorizam a crítica radical à atual expansão ilimitada : das relações mercantis. Ora, se a crítica à merФ્ cantilização desenfreada das relações sociais aproxima a abordagem de Santos da de Gorz, emancipação. Nunca é demais acrescentar os vínculos que os dois tinham com as formulações de Ivan Illich e sua ideia de convivialidade, hoje recuperada por Alain Caillé. Assim, a despeito das terminologias distintas, há muito em comum em suas formulações.

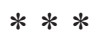

Voltando a Gorz, pode-se dizer que (1) a redução generalizada do tempo de trabalho e (2) a garantia de uma renda social incondicional são, doravante, objetivos fundamentais de uma política emancipatória porque elas se tornaram condições necessárias na busca da autonomia individual e coletiva. No entanto, elas, em si mesmas, não são garantidoras de autonomia, podendo mesmo ser reabsorvidas pelo sistema. Por essa razão, ele as concebia como meios que, ao diminuírem a importância do vínculo com o mercado de trabalho assalariado, possibilitam (3) o florescimento de atividades autônomas, capazes de reforçar os vínculos sociais e de contribuir para o desenvolvimento de uma esfera livre das relações mercantis. As três políticas formam, conjuntamente, uma proposta unitária de mudança social anticapitalista.

Tal proposta, concebida no mesmo registro das reformas revolucionárias, atendia, em vários sentidos, às exigências de seu diagnóstico do presente. Em primeiro lugar, num contexto de desemprego estrutural e tecnológico, a redução generalizada do tempo de trabalho e a garantia de renda social incondicional são as formas de dar continuidade à lógica da "desmercadorização" da força de trabalho, que caracterizava alguns modelos de Estado de bem estar (Esping-Andersen, 1990), contrapondo-se, assim, à lógica da "desmercadorização” perversa, típica das políticas neoliberais que o faziam simplesmente excluindo os trabalhadores reais ou potenciais do mercado de trabalho (Offe, 1985). Em segundo lugar, com a redução do trabalho socialmente necessário, 
decorrente das inovações tecnológicas e das novas formas de gestão, ambas poupadoras de trabalho, a tradicional solução da crise de desemprego pela via do crescimento econômico torna-se cada vez menos plausível, porque o crescimento econômico não mais se traduz em crescimento ou manutenção do nível de empregos. Mas, além de implausível, o combate ao desemprego por meio do crescimento econômico pode também não ser desejável, principalmente se produzir efeitos danosos para o ambiente natural. É justamente esse o sentido da crítica ao produtivismo, conforme suas reflexões em torno da ecologia política (Gorz, 2010; Gollain, 2000; Münster, 2008). Dessa forma, sua análise indica que a autonomia ou emancipação deve ser buscada não na esfera do trabalho assalariado, mas em atividades que permitam a autogestão da vida.

Também não é demais lembrar que, na década de 1960, quando Gorz elaborou pela primeira vez a ideia de reformas revolucionárias, suas propostas tinham um claro destinatário: o proletariado, sobretudo dos países europeus de então. Depois de seu "adeus ao proletariado" em 1980, suas propostas deixaram de ter aquele destinatário anterior privilegiado. Mas, para serem efetivas, as propostas atuais não podem deixar de considerar possíveis destinatários. E, durante esse período pós-adeus ao proletariado, Gorz referiu-se a alguns deles, indo desde a "não classe de não trabalhadores", no livro de 1980, até às comunidades hackers, em escritos mais recentes (Gorz, 2010; Gianinazzi, 2016). Creio que aqui, na verdade, sua referência são os movimentos sociais mais recentes, cujas pautas de reivindicações podem convergir em certos aspectos com suas proposições, entre os quais se destacam os movimentos ecológicos ou verdes, com os quais ele manteve sempre uma forte interlocução, constituindo, portanto, claros destinatários de sua teoria. Enfim, para concluir, creio que o conceito de reformas revolucionárias elaborado por Gorz na década de 1960 continua sendo um útil instrumento para a análise crítica do capitalismo e suas mazelas, assim como uma bússola a indicar caminhos possíveis e plausíveis para sua superação.

Recebido para publicação em 05 de junho de 2017 Aceito em 25 de julho de 2017

\section{REFERÊNCIAS}

ADRET. Travailler deux heures par jour. Paris: Éditions du Seuil, 1977.

AMORIM, H.Trabalho Imaterial: Marx e o debate contemporâneo. São Paulo: Annablume, 2009.

CAILLÉ, A. Anthropolgie du don. Le tiers paradigme. Paris: Desclée de Brouwer, 2000.

CAILLÉ, A. Au-delà du marxisme et du capitalisme. In: CAILLÉ, A.; FOUREL, C. (Ed.). Sortir du capitalisme: Le scénario Gorz. Lormont: La Borde de L’eau, 2013. p. 189198.

CAILlÉ, A. Anti-utilitarisme et paradigme du don. Pour quoi? Lormont: La Borde de L'eau, 2014.

CAMARGO, S. Trabalho imaterial e produção cultural: a dialética do capitalismo tardio. São Paulo: Annablume, 2011.

CONTI, L. Les conditions du dévelopment culturel en Union Soviétique. Les Temps Modernes, [S.1.], n. 209, p. 707-719, 1963.

DELORS, J. (Dir.). La révolution du temps choisi. Paris: Éditions Albin Michel, 1980.

ESPING-ANDERSEN, G. The Three Worlds of Welfare Capitalism. Princeton: Princeton University Press, 1990.

FRASER, N. Struggle over Needs: Outline of a SocialistFeminist Critical Theory of Late Capitalist Culture. In: FRASER, N. Unruly Practices. Minneapolis: University of Minnesota Press, 1989. p. 161-187.

FRASER, N. From Redistribution to Recognition? Dilemmas of Justice in a 'Post-Socialist' Age, New Left Review, [London], n. 212, p. 68-95, 1995.

FRASER, N. Social Justice in the Age of Identity Politics: Redistribution, Recognition, and Participation. In: FRASER, N.; HONNETH, A. Redistribution or Recognition? A Political-Philosophical Exchange. London; Verso, 2003. p. 7-109.

GIANINAZZI, W. André Gorz: Une vie. Paris: La Découverte, 2016.

GOLLAIN, F. Une, critique Du travail: Entre écologie et socialisme. Paris: Éditions La Découverte, 2000.

GORZ, A. Stratégie ouvrière et néocapitalisme. Paris: Éditions du Seuil, 1964.

GORZ, A. Le socialisme difficile. Paris: Éditions du Seuil, 1967.

GORZ, A. Estratégia operária e neocapitalismo. Rio de Janeiro: Zahar Editores, 1968a.

GORZ, A. O socialismo difícil. Rio de Janeiro: Zahar Editores, 1968b.

GORZ, A. Réforme et révolution, Paris, Éditions du Seuil, 1969.

GORZ, A. Écologie et liberté. Paris: Galilée, 1977. 
GORZ, A. Adieux au prolétariat. Au-délà du socialisme. Paris: Galilée,1980.

GORZ, A. Néuf thèses pour une gauche future, Les Temps Modernes, Paris, n. 416, p.1541-1554, 1981.

GORZ, A. Les chemins du Paradis: L'agonie du Capital. Paris: Galilée, 1983.

GORZ, A. Métamorphoses du travail: Quête du Sens. Critique de la raison économique. Paris: Galilée, 1988.

GORZ, A. Capitalisme, Socialisme, Ecologie:Désorientations, Orientations. Paris: Galilée, 1991.

GORZ, A. On the difference between Society and Community, and why basic income cannot by itself confer full membership of either. In; VAN PARIJS, P. (Ed.). Arguing for basic income. London: Verso, p. 178-184. 1992.

GORZ, A. Revenu minimum et citoyenneté: Droit au travail vs. droit au revenu. Futuribles, [S.l.], n. 184, p. 4960, 1994.

GORZ, A. Misères du présent: Richesse du possible. Paris: Galilée, 1997.

GORZ, A. L'immatériel: Connaissance, valeur et capital. Paris: Galilée, 2003.

GORZ, A. Penser l'exode da la société du travail et de la marchadise. Mouvements, [S.l.], n. 50, juin/août 2007b. Disponível em: <http://mouvements.info/spip.php?article 65>. Acesso em: 4 dez. 2007a.

GORZ, A. Crise mondiale, décroissance et sortie du capitaslime, Entropia, [S.1.], n. 2, p.51-59, 2007b.

GORZ, A. Écologica. Paris: Galilée, 2010.

HOWARD, D. New Situation, New Strategy: Serge Mallet and André Gorz. In: HOWARD, D.; KLARE, K. E. (Ed.) The Unknown Dimension: European Marxism since Lenin. New York, Basic Books, 1972. p. 388-413.

LANGER, A. Pelo êxodo da sociedade salarial. A evolucão do conceito de trabalho em André Gorz. Cadernos IHU, São Leopoldo, RS, ano 2, n. 5, 2004.

LUXEMBURG, R. Reforma, revisionismo e oportunismo. Rio de Janeiro: Laemmert, 1970

MACHADO, N. M. C. A obra de Gorz da década de 2000 e a sua relação com a nova crítica do valor. Revista Pós Ciências Sociais, São Luís, v. 13, n. 25, p. 277-304, 2016.

A MARX, K. Capital. New York: International Publishers, ร) 1967. v. 3

৯ MÜNSTER, A. André Gorz ou le Socialisme difficile. ๑ Clamecy: Nouvelles Éditions Lignes, 2008.

\& OFFE, C. Contradictions of the Welfare State. Cambridge: क MIT Press, 1984

?ָ 소 1985a.
OFFE, C. Full Employment: Asking the wrong question? Dissent, [S.l.], p. 77-81, 1995.

OFFE, C. et al. Time, Money, and Welfare-State Capitalism. In: KEANE, J.(Ed.). Civil Society and the State. London: Verso, 1988. p. 221-243.

OFFE, C; HEINZE, R. G. Beyond Employment: Time, Work and the Informal Economy. Philadelphia: Temple University Press, 1992.

RODRIGUES, I. J. Estratégia operária e neocapitalismo, Tempo Social, São Paulo, v. 21, n. 1, p. 51-64, 2009.

ROUSSELET, J. L'Alergie au travail. Paris: Éditions du Seuil, 1974.

SANTOS, B. de S. A crítica da razão indolente: contra o desperdício da experiência. São Paulo: Cortez, 2000.

SANTOS, B. de S. A difícil democracia: reinventar as esquerdas. São Paulo: Boitempo, 2016.

SANTOS, B. de S. O fórum social mundial: manual de uso, São Paulo: Cortez, 2005.

SANTOS, B. de S. A gramática do tempo: para uma nova cultura política. São Paulo: Cortez, 2006.

SCHEHR, S. La vie quotidienne des jeunes chômeurs. Paris: PUF, 1999.

SILVA, J. P. da. André Gorz: trabalho e política, 2. ed. São Paulo: Annablume, 2011.

SILVA, J. P. da. André Gorz e renda básica: uma história de conversão crítica. In: SILVA, J. P. da. Por que renda básica? São Paulo: Annablume, 2014a. p. 63-83.

SILVA, J. P. da. Epistemologia do sul como teoria crítica? nota crítica sobre a teoria da emancipação de Boaventura de Sousa Santos. Trabalho apresentado ao $40^{\circ}$ Encontro Anual da Anpocs, 2014. Caxambu, MG. Caxambu, MG, 2014b.

SILVA, J. P. da. O que é crítico na sociologia crítica? Revista Brasileira de Ciências Sociais, São Paulo, v. 32, n. 93, p. 1-18, 2017.

SILVA, J. P. da. Tensão entre tempo social e tempo individual. Tempo Social, São Paulo, v. 21, n. 1, p. 35-50, 2009.

SILVA, J. P. da. Três discursos, uma sentença: tempo e trabalho em São Paulo - 1906/1932. São Paulo: Annablume: Fapesp, 1996.

SILVA, J. P. da. Tempo de trabalho e imaterialidade na teoria social de André Gorz. Caderno CRH, Salvador, v. 27, n. 70, p. 101-113, 2014c

SILVA, J. P. da. Trabalho, cidadania e reconhecimento. São Paulo: Annablume, 2008.

WRIGHT, E. O. Basic Income as a Socialist Project. Basic Income Studies, [S.l.], v. 1, n. 1, p. 1-11, 2006a.

WRIGHT, E. Compass Points, New Left Review, London, n. 41 p. 93-124, 2006b. 


\section{NOTE ON THE CONCEPT OF 'REVOLUTIONARY REFORMS' OF ANDRÉ GORZ}

\author{
Josué Pereira da Silva
}

The article deals with the contemporary relevance of the concept of "revolutionary reforms", formulated by André Gorz in the 1960s, and resumed in his more recent writings. My theses here is that such concept remains actually valid, and it has been, direct or indirectly, appropriated by other social-theorists, though sometimes using a different language. To develop my argument, I begin by presenting the contours of the concept. Then, I show how Gorz uses it along with his writings. And to conclude, I discuss it through the works of other authors by focusing on some themes of contemporary debates.

KeY wORDS: André Gorz. Revolutionary reforms. Labor time. Basic Income.

\section{NOTE SUR LE CONCEPT DE 'RÉFORMES REVOLUTIONAIRES' D’ANDRÉ GORZ}

\author{
Josué Pereira da Silva
}

L'article s'occupe de la rélevance contemporaine du concept gorzian de "réformes révolutionnaires" qu'il avait formulé pendant les annés 1960s, et qu'il reprendre dans ses derniers écrits. La thèse que je veux défendre ici c'est que ce concept est encore actuel et qu'il a eté approprié par d'autres théoriciens contemporaines, même s'ils employent un langage différent. Pour developper mon argument, je commence en présentant les traits du concept. En suite, je montre comment Gorz use le concept dans ses écrits pendand le temps. Pour conclure, je discute le concept en lui confrontant avec les travaux d'autres auteurs à l'aide de quelques thèmes contemporains.

Mots-CLÉs: André Gorz. Réformes révolutionnaires. Temps du travail. Revenu social garanti.

Josué Pereira da Silva - Doutor em Sociologia pela New School for Social Research, New York, USA. Professor do Departamento de Sociologia da Universidade Estadual de Campinas (UNICAMP). Integra o Núcleo de Pesquisa Teoria Crítica e Sociologia (HTTP://www.tcesociologia.ifch.unicamp.br), desenvolvendo pesquisas na área de Teoria social crítica e Sociologia contemporânea. Publicações recentes: Por que renda básica? (Annablume, 2014); Trabalho, cidadania e reconhecimento (Annablume, 2008); André Gorz: trabalho e política, 2a . Edição (Annablume, 2011). 
